\title{
Vessels for the Storage and Transport of Liquid Hydrogen
}

\author{
B. W. Birmingham, E. H. Brown, ${ }^{\prime}$ C. R. Class, ${ }^{2}$ and A. F. Schmidt
}

\begin{abstract}
The design and construction of a large-scale hydrogen liquefier by the National Bureau of Standards required a concurrent development of large, transportable liquid-hydrogen containers. These containers, known as Dewar vessels after the inventor, James Dewar, had to be capable of road and air transport, which implied ruggedness and light weight. This article reports on large-scale liquid-hydrogen Dewar development conducted by the NBS Cryogenic Engineering Laboratory. A 440-liter and an 840-liter Dewar are discussed. Every effort has been made to design Dewars with very low hydrogen-loss rates within the limitations of the transport requirement.
\end{abstract}

\section{Dewar Configuration}

The optimum Dewar configuration is spherical, because the sphere has the smallest area-to-volume ratio of any shape. In practice, however, such theoretical configurations must be tempered by the commercial availability of variously shaped metal heads. The shape of each of the NBS Dewars [1] ${ }^{3}$ was governed by different considerations. The 440liter Dewar was designed around readily available commercial heads. The 840-liter Dewar was designed to fit a specific space and required special tooling for head fabrication. Figures 1 and 2 show Dewar cross sections; figures 3 and 4 show the completed Dewars.

\section{Insulation Methods}

Only two methods of Dewar insulation appeared feasible at the time of the design: the use of powder insulation, such as silica aerogel, at a moderate vacuum, and the use of an unfilled space at a high vacuum. Although the moderate vacuum associated with powder insulation brings many advantagessuch as reducing the importance of very minute leaks and making the achievement of a static vacuum easier - the insulation value when used in moderate thickness does not appear to be as great as that of an unfilled space at a high vacuum (up to about $0.01-\mu \mathrm{Hg}$ pressure) with surfaces having a high reflectivity (low emissivity). As one of the primary goals was the achievement of a low hydrogen loss without making the Dewar too bulky, high vacuum rather than evacuated powder was chosen for the Dewar insulation.

With high-vacuum insulation, heat energy flows to the inner surfaces by three mechanisms: thermal radiation, residual gas conduction, and solid conduction through piping and insulating supports.

Without any shielding, thermal radiation from room temperature directly to the liquid-hydrogen container would be excessive and would make it difficult to develop a low-loss hydrogen Dewar. In order to reduce this thermal radiation, a liquidnitrogen-cooled radiation shield was planned. 'This shield completely surrounds the liquid-hydrogen

\footnotetext{
1 Work supported by the U. S. Atomic Energy Commission and the U. S. Air Force.

2 Now with Beech Aircraft Corp.

3 Figures in brackets indicate the literature references at the end of this paper.
}

container and intercepts all ambient temperature radiation from the outer shell. Thermal radiation to the liquid-hydrogen container is then reduced by a factor of at least 200 and becomes of the same order of magnitude as the residual gas conduction and the solid conduction.

When considering heat transfer to the nitrogencooled shield, residual gas conduction for a vacuum of the order of $0.01-\mu \mathrm{Hg}$ is relatively unimportant compared with thermal radiation. A low heat leak to the nitrogen-cooled shield therefore requires highly reflecting surfaces. Throughout the NBS Dewar development program high insulating vacuums and surfaces of high reflectivity were emphasized.

\section{Materials of Construction}

Several factors must be considered in varying degrees in regard to the materials of construction of Dewar vessels. Mechanical properties, thermal conductivity, surface reflectivity, out-gassing rates, and diffusion properties are some of the more important factors. For equipment designed for transport, another factor-weight - is also of considerable importance.

Among the various mechanical properties of metals, brittleness or notch sensitivity is one of the most important in cryogenic work, because many metalsnotably the ferritic steels-become very brittle just below room temperature. Some of the common engineering metals whose impact strengths (as measured by Charpy or Izod notch tests) are satisfactory down to liquid-hydrogen temperatures, are austenitic steels (such as the stainless types, 304, 316, 321, and 347), copper, many copper alloys, and aluminum.

For piping, good strength and low thermal conductivity are necessary. Of the more common materials, stainless steel and Monel have these characteristics. Of these two, Monel not only has a thermal conductivity approximately twice that of stainless steel, but it is also more expensive. 'Thus, in the absence of any other compelling factors, stainless steel is ordinarily used for all internal piping.

The choice of shell materials is more difficult because a greater number of factors are involved. For low weight, aluminum is indicated. For high reflectivity, both copper and aluminum are good, but aluminum probably maintains its reflectivity better 


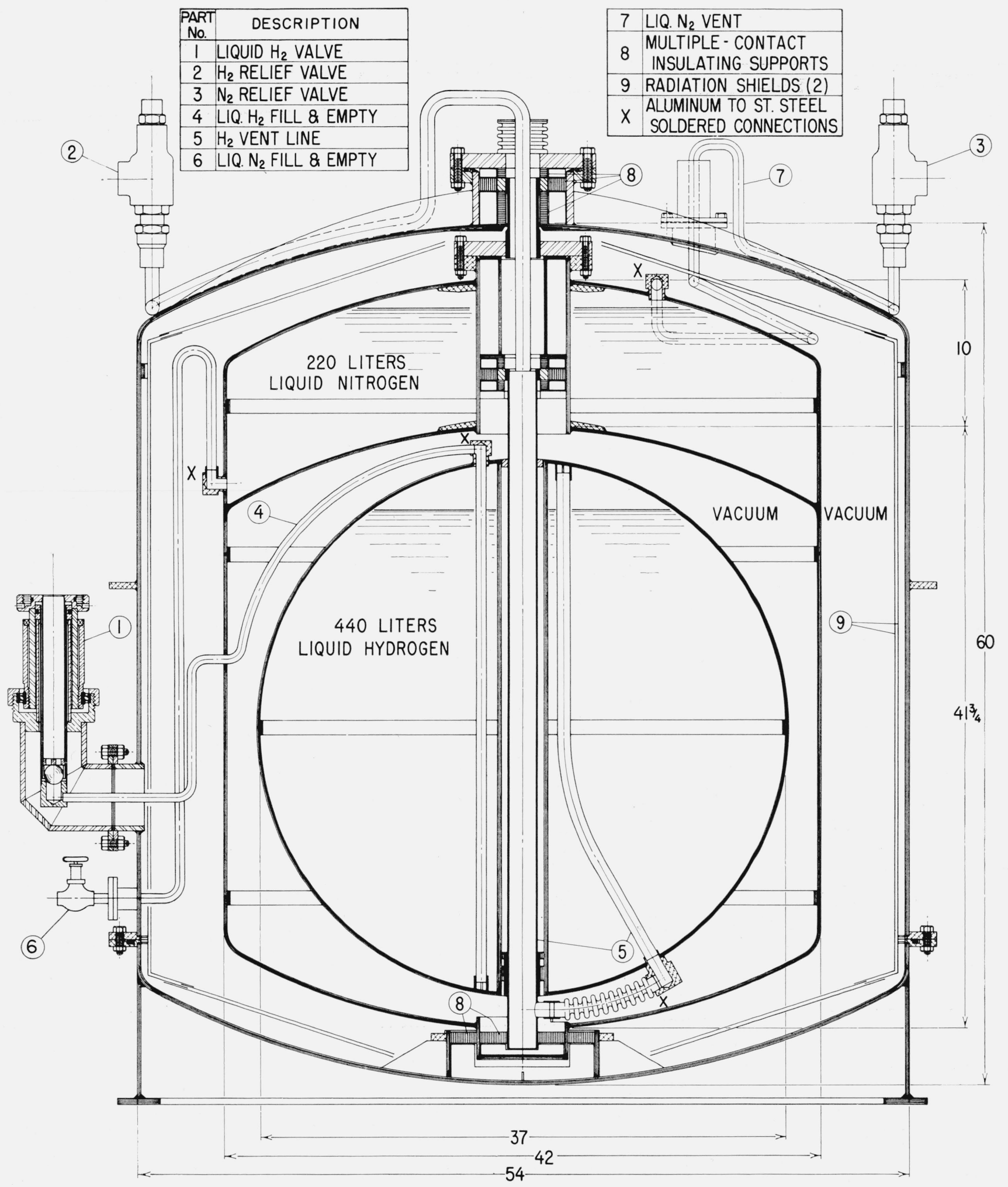

Figure 1. 440-liter liquid hydrogen Dewar. 


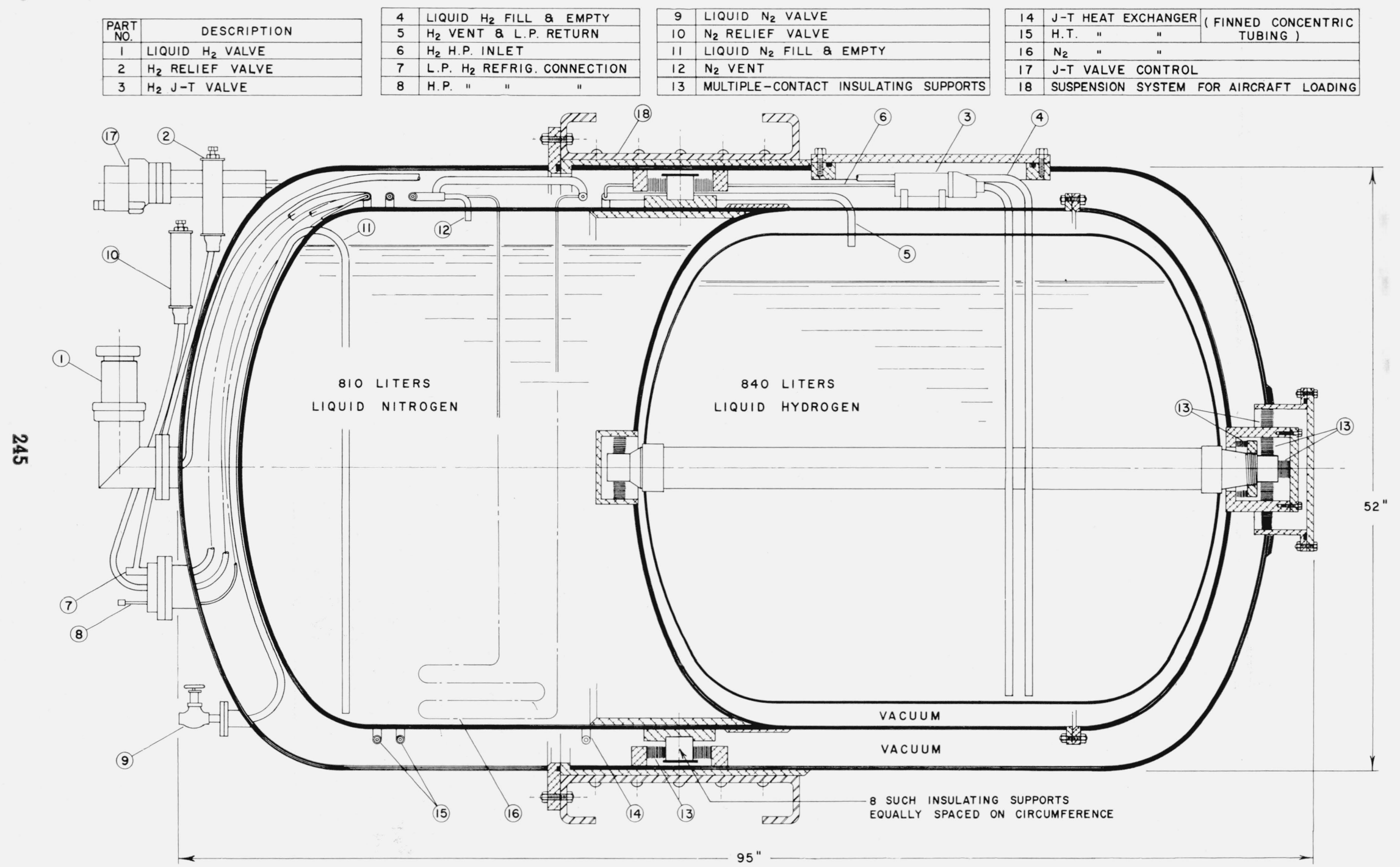

Figure 2. 840-liter liquid hydrogen Dewar. 
Figure 3. 440-liter liquid hydrogen Dewar.

A, Liquid-level gages $\left(\mathrm{N}_{2}\right.$ and $\left.\mathrm{H}_{2}\right)$; B, pressure gages $\left(\mathrm{N}_{2}\right.$ and $\mathrm{H}_{2}$ ); $\mathrm{C}$, weight-loaded relief valve; D, insulating vacuum gage: $\mathrm{E}$, auxiliary vacuum pump connection; $\mathrm{F}$, blowers; $\mathrm{G}$, shielded air-cooled diffusion pump; $\mathrm{H}$, mechanical vacuum pump; I, liquid $\mathrm{N}_{2}$ fill-and-discharge valve; J, electrical system switch panel and vacuum gage control unit; $\mathrm{K}$, system switch panel and vacuum gage control unit; $\mathrm{K}$, valves $\left(\mathrm{H}_{2}\right.$ and $\left.\mathrm{N}_{2}\right)$.
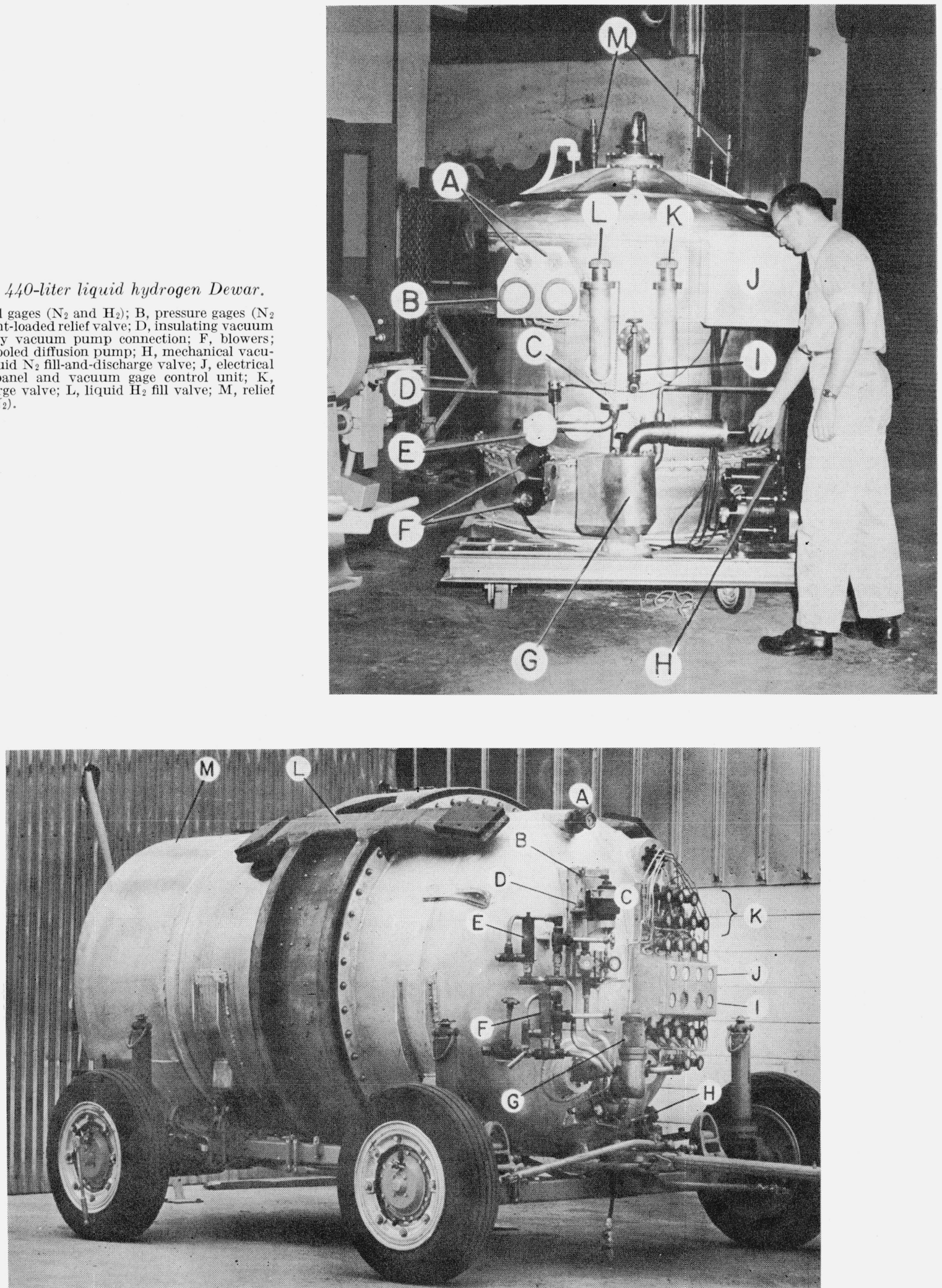

FIgURE 4. 840-liter liquid hydrogen Dewar.

A, J-T valve control; B, H. P. $\mathrm{H}_{2}$ refrigerator connection; C, H. P. $\mathrm{H}_{2}$ line filter; D, L. P. $\mathrm{H}_{2}$ refrigerator connection; E, N2 relief valve; F, $\mathrm{H}_{2}$ relief valve; G, liquid $\mathrm{H}_{2}$ fill and discharge valve; $\mathrm{H}$, liquid $\mathrm{N}_{2}$ fill and discharge valve; $\mathrm{I}$, liquid level and pressure gages $\left(\mathrm{H}_{2}\right.$ and $\left.\mathrm{N}_{2}\right) ; \mathrm{J}$, pressure gages for monitoring refrigeration process; $K$, refrigerator heat exchanger warmup connections; $L$, suspension system for aircraft loading; $M$, vacuum pumping system enclosure. 
than copper. It is possible to use stainless steei covered with aluminum foil to obtain a high reflectivity. For high thermal conductivity, which is desirable in some places, either copper or aluminum can be used. Finally, because the solubility of hydrogen in aluminum is much less than that in stainless steel [2], aluminum should be a very good material with respect to hydrogen diffusion.

For the outer shell, where low weight and high reflectivity are important, aluminum would appear to be the ideal material. For the liquid-nitrogen-cooled radiation shield, low weight, high reflectivity, and high thermal conductivity are desirable. The latter factor-high thermal conductivity - is important because the liquid nitrogen is in contact with only a restricted area of the shield, which means that thermal energy reaching the remainder of the shield must flow to the liquid nitrogen by solid conduction. This combination of requirements again indicates aluminum.

For the liquid-hydrogen container, high reflectivity, low hydrogen diffusion, and, again, high thermal conductivity are the important factors. Liquid hydrogen when kept in a shell of relatively low conductivity, i. e., stainless steel, supports a temperature gradient that is undesirable when the vessel is sealed to allow pressure buildup. The top layer of the liquid may be as much as 1 to $1 \frac{1}{2} \mathrm{deg} \mathrm{C}$ warmer than the bottom layer, and the vapor pressure in the vapor space above the liquid is correspondingly bigh. This pressure buildup is undesirable in a sealed-off container because it causes the safety valves to relieve the vessel prematurely, and in a refrigerated vessel causes the refrigerator to cycle more frequently. In stainless or other poorly conducting shells, this stratification can be overcome by thermal equilibratorsvertical copper or aluminum sheets or rods which conduct heat from the top to the bottom of the liquid-but it is simpler, if possible, to accomplish this by use of a good thermal-conductivity material in the shell itself, e. g., aluminum or copper.

Because of the above combination of reasons it was decided to fabricate most of the Dewar shells from aluminum. The particular type of aluminum chosen was the weldable alloy $52 \mathrm{~S}$, which in liquid oxygen equipment had been found to be even less susceptible than $61 \mathrm{~S}$ to cracking in the welds at low temperatures. Although aluminum had been used extensively in liquid-oxygen plants and Dewars, as mentioned by Gillette [3], this appears to be the first time its use was considered both for liquid-hydrogen temperatures and for high-vacuum vessels. The solution of the one foreseeable problem that arose because of this choice, transition joints between aluminum shells and stainless steel tubing, is discussed below.

\section{Insulating Supports}

Acceleration, shock, and vibration conditions can be quite severe in equipment subject to road and air transport. For instance, the following mechanical service conditions were imposed as 840-liter Dewar design objectives:
(1) Acceleration:

(a) Vertical accelerations from $-3 \mathrm{~g}$ to $+5 \mathrm{~g}$, including acceleration of gravity.

(b) Horizontal accelerations from $-4 \mathrm{~g}$ to $+4 \mathrm{~g}$.

Accelerations are continuously applied for periods not exceeding 1 sec.

(2) Shock:

Shocks of $5 \mathrm{~g}$ applied in either direction along three mutually perpendicular axes, with each shock being from 10 to 15 msec duration.

(3) Vibration:

(a) 0.05-in. double amplitude (total excursion) from 5 to 10 cps.

(b) 0.036 -in. double amplitude from 10 to $75 \mathrm{cps}$.

Vibration continuous in any one or all of three mutually perpendicular planes.

Thus it is readily seen that a Dewar capable of road and air transport requires a sturdy suspension system (i. e., a system for supporting one shell from another). This suspension system must also be a good thermal insulator in order to minimize conduction heat leak to the cold shells. From a mechanical viewpoint it is desirable to have the suspension system rigid to eliminate the possibility of internal resonances that could be caused by vibration during transport, and from an assembly viewpoint the suspension system should be simple.

For the suspension system used on the NBS Dewars, there appeared to be a choice between either stainless-steel cables or rods, or multiplecontact thermal insulators which have been developed by the NBS Cryogenic Engineering Laboratory. Stainless-steel cables have been employed very successfully, from a thermal point of view, in liquidhydrogen transport Dewars. However, their use has resulted in two major difficulties. First, getting the proper distribution of tension on all support cables causes a very difficult assembly problem. Second, experience has shown that such cables may be stretched considerably under repeated loading and thermal cycling. This stretching lowers the natural frequency of the suspension system and makes it difficult for the Dewar to meet acceleration and shock specifications.

Some remarks on the development of multiplecontact thermal insulators by the Bureau might be of interest. During various experiments it has been observed that difficulty is experienced in transferring heat across metal surfaces clamped together in supposedly good contact in a vacuum. The surfaces may appear quite smooth and yet, due to microscopic irregularities, may present only a small area of metalto-metal contact; thus, the net area for solid conduction is quite small. This area depends on load and metal hardness. When one multiplies this effect by lamination, rigid members that are also good thermal insulators can be readily devised. Preliminary experiments by the NBS Cryogenic Engineering Laboratory have indicated that the apparent thermal conductivity of a laminated stainless steel or Monel insulating support under high unit loads (1,000 psi) would be about one-fiftieth that of the metal itself [4]. Further experiments [5] indicate that, by proper 

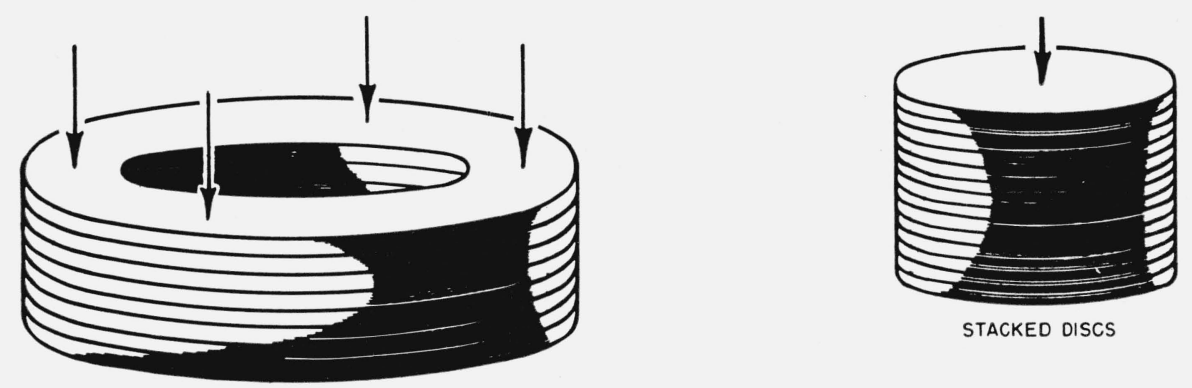

STACKED WASHERS
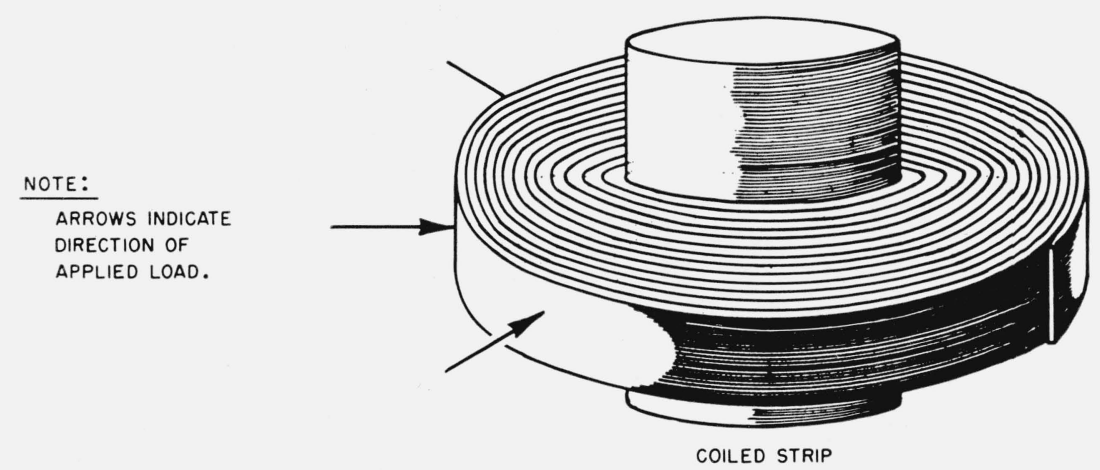

Figure 5. Insulating supports.

design (dusted surfaces and moderate unit loads), ratios as low as one two-hundredth of the base metal can be achieved.

The insulating supports developed for the NBS Dewars were rigid laminae formed from thin stainless steel $(0.002$ to 0.005 in. thick). Washers and disks were used to support axial loads, and tightly wound coils were used to support loads that were radial (with respect to the coil) (see fig. 5).

\section{Joining Aluminum to Stainless Steel}

To use metallic tubing of low thermal conductivity such as stainless steel in Dewars of aluminum-alloy shell construction, it is necessary to make aluminumto-stainless-steel tubing joints that will remain vacuum-tight over a possible range of $+130^{\circ}$ to $-420^{\circ} \mathrm{F}$. Because the coefficient of thermal expansion of aluminum and most of the common aluminum alloys is approximately 50 percent greater than that of stainless steel, the joint must be sufficiently ductile to withstand all stresses imposed upon it by thermal expansion and contraction. In addition, the joint must be designed to accommodate an amount of vibration and shock loading commensurate with specified service requirements. Finally, the simplicity and ease of actually making the joint is a desirable and almost essential feature, as some form of field repair work may prove necessary upon occasion.

Four basic methods of joining aluminum to stainless steel have been successfully used, each of which employs soft solder as the filler material. (For a survey of methods of joining aluminum to stainless steel, see [6].) In all cases, the aluminum and stainless-steel tubing were initially of the same nominal size; however, prior to the joining operation, the aluminum tube was swaged out at one end for a length of approximately $1 \mathrm{in}$. so that it would fit easily over the outside diameter of the stainless-steel tube, thus forming a tubular lap joint (see fig. 6). In an aluminum-to-stainless-steel connection such as is described here, it is of definite value to utilize the aluminum as the outer member, because in cooling from the soldering temperature to room temperature, and eventually from room temperature to $-420^{\circ} \mathrm{F}$, the joint tends to close up and become even tighter than when fabricated, due to the greater contraction taking place in the aluminum as compared with the stainless steel.

In brief, the four joining methods are as follows: (1) To eliminate the usual amount of difficulty involved in effectively tinning aluminum, the portion of aluminum to be used is first copperplated in an approved manner, thus providing an excellent soft solder base. Subsequent tinning of the copperplated area and the stainless-steel member provides the basis for a satisfactory joint. (2) An alternative method to that described above concerns the use of ultrasonic soldering equipment, which removes the troublesome aluminum oxide layer by cavitation, thereby permitting the oxide-free aluminum alloy to be tinned directly. (3) When it is found necessary to make, or repair, an aluminum-to-stainless-steel connection without benefit of copperplating or ultrasonic equipment, such as in the field, friction tinning can be of value. In this method, molten solder is applied to the aluminum working surface 


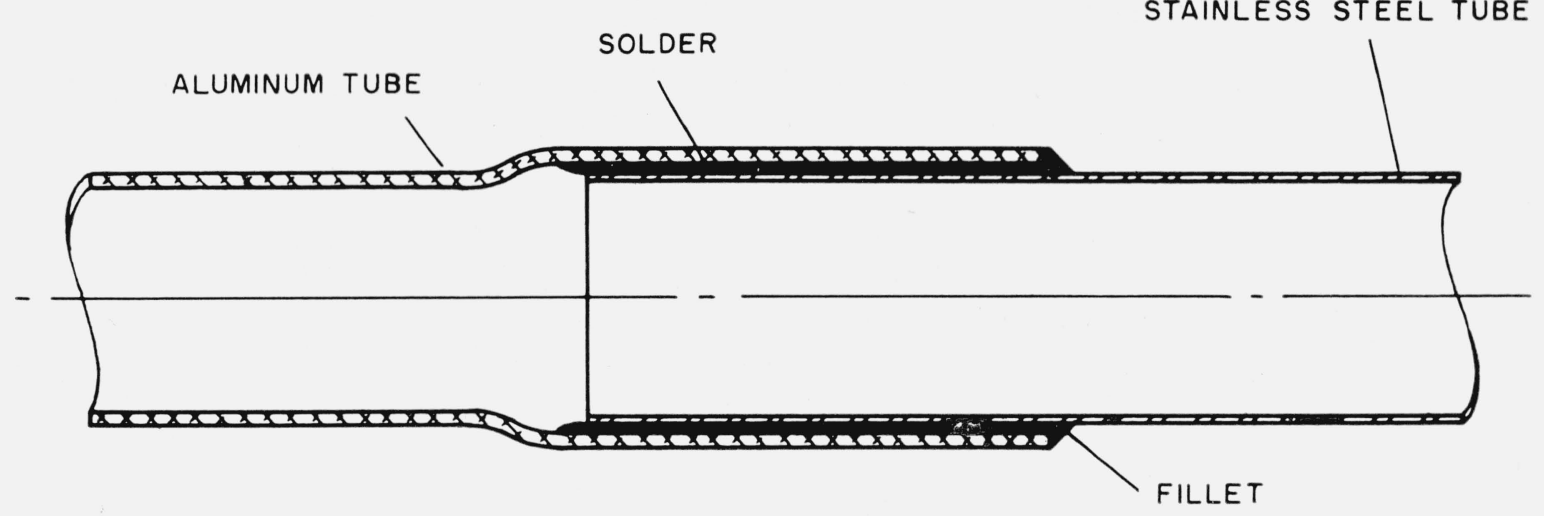

Figure 6. Tubular lap joint.

and a sharp implement is used to rub the surface free of oxide beneath the solder, again permitting the oxide-free aluminum alloy to be tinned directly.

In order to avoid the annoying and ever-present possibility of oxidizing the stainless steel when making the joint, it is often beneficial to use a copper transition, or intermediate member in the connection. The copper sleeve may be joined either to the inner or outer surface of the stainless steel by suitable silver brazing technique, and the free end is tinned with soft solder. The joint is made after treating the aluminum portion as in (1), (2), or (3) above.

A number of other methods have been tried for this type of work, some of which have been erratic in reproducibility and others of which have met with little or no success.

Possibly one of the more desirable methods of making a bimetallic joint involves the molecular bonding of aluminum and its alloys to steel. In this process, the aluminum is cast by any of the standard casting methods, against a specially prepared, clean, ferrous surface. In this manner, any practicable aluminum form can be incorporated into the joint design. Tests on a preliminary batch of 5 such bimetallic joints indicated that 4 remained vacuumtight between room temperature and $-320^{\circ} \mathrm{F}$, and 1 leaked at any temperature. A very poor intermetallic bond was observed on the one failure that occurred, but the remaining four appeared good.

It appears that the best method of joining aluminum and stainless steel depends greatly upon the application involved as well as the availability and suitability of equipment to do the particular job. Although it is not necessary to employ an expert to fabricate connections of this type, a certain amount of skill and care is of considerable value in doing good work.

\section{Auxiliary Design Features}

The transfer of liquid hydrogen from these large vessels is usually accomplished by increasing the gas pressure in the free space above the liquid until it is sufficient to force the liquid through an insulated transfer line to the receiving vessel at a lower pressure. A simple, convenient method for pressurizing has been developed at the Bureau. It consists of a circulating pump, which withdraws cold hydrogen gas from the Dewar through a copper warmup tube and then returns the gas to the space above the liquid in the Dewar. In such a system, for every standard cubic foot of hydrogen gas circulated, about $2.5 \mathrm{whr}$ is available to cause evaporation. This raises the pressure over the liquid. If pressurized quickly enough, only the top layer of liquid hydrogen will come to equilibrium with the vapor. This technique makes possible the transfer of subcooled liquid hydrogen and results in smaller losses than when transferring liquid hydrogen at saturation temperature.

The pump used with the 440-liter Dewar is a 1/3-hp oilless diaphragm paint-sprayer compressor with a 5.8-cfm free gas displacement. The pump is small and compact enough to be permanently mounted on the Dewar. The time required to pressurize the full Dewar from 1 to 15 psig is about $3 \mathrm{~min}$. The time required to pressurize the Dewar when half-full or nearly empty is somewhat longer. Transfer rates of over 2,000 liters/hr have been accomplished with this pressurizing technique.

One of the predominantly experimental features of the 440-liter Dewar is centered around the use of two liquid-hydrogen lines, one at the top, the other at the bottom of the hydrogen container. Prior to fabrication, various theories existed as to the desirability of filling the liquid-hydrogen container from the top rather than from the bottom, and vice versa. If the filling takes place from the top, a great deal of splashing occurs, and an additional line at the bottom is required to empty the Dewar. If, on the other hand, the filling takes place from the bottom, flash vapor from the transfer operation bubbles through the liquid as it collects in the container, possibly entraining liquid and carrying it out the vent line. However, the vessel may be emptied through the same line. Contrary to speculation, no difference was noted between top and bottom ports in the filling operation, so it appears advisable to use a single valve and line leading to the bottom of the hydrogen container for both filling and emptying. 
The insulating vacuum of each Dewar was provided by an air-cooled oil-diffusion pump having a rated speed of 260 liters/sec, together with associated forepump, valves, and safety features. The 840liter Dewar was required to operate at ambient temperatures up to $130^{\circ} \mathrm{F}$, at which temperature considerable backstreaming of oil vapor from the diffusion pump was found in laboratory tests. To prevent the oil from condensing on the cold goodreflective surfaces in the Dewar and thereby raising the emissivities, a baffle cooled by metallic contact with the liquid-nitrogen-cooled shield was installed in the pumping line to the Dewar vacuum space.

\section{Thermal Calculations}

Preliminary heat-transfer studies were carried out on various support and insulation methods in order to obtain predicted values for the heat flow into the liquid-nitrogen-cooled shield and the liquid-hydrogen container of each Dewar. As mentioned above, the heat flow to each of these shells can be broken down into three mechanisms: (1) Thermal radiation, (2) residual gas conduction, and (3) heat flow through piping and insulating supports.

For heat-transfer calculations the Dewars may be considered as two separate units. The first unit consists of a liquid-nitrogen container at $77^{\circ} \mathrm{K}$ surrounded by the outer shell at $300^{\circ} \mathrm{K}$; the second, a hydrogen container at $20^{\circ} \mathrm{K}$ surrounded by the liquid-nitrogen-cooled shield at $77^{\circ} \mathrm{K}$. Each of these units is considered separately in calculations because the two important figures in the results are the evaporative loss rates of liquid nitrogen and liquid hydrogen.

\subsection{Radiation}

Radiant energy transfer may be calculated from the Stefan-Boltzmann equation,

where

$$
\dot{Q}=\sigma \epsilon A_{1}\left(T_{2}^{4}-T_{1}^{4}\right)
$$

$$
\begin{aligned}
\dot{Q} & =\text { watts } \\
\sigma & =0.0037 \times 10^{-8} \mathrm{w} \text { in. } \\
\epsilon & =\text { emissivity factor, } \\
T_{1} & =\text { temperature of inner surface in degrees } \mathrm{K}, \\
T_{2} & =\text { temperature of outer surface in degrees } \mathrm{K}, \\
A_{1} & =\text { area of inner surface in square inches. }
\end{aligned}
$$

The emissivity factor used in the above equation is obtained from a correction formula developed by Christiansen [7] for concentric spheres and cylinders:

$$
\frac{1}{\epsilon}=\frac{1}{\epsilon_{1}}+\frac{A_{1}}{A_{2}}\left(\frac{1}{\epsilon_{2}}-1\right),
$$

where the subscripts 1 and 2 refer to the inner and outer surfaces, respectively. A value of 0.04 for $\epsilon_{1}$ and $\epsilon_{2}$ was used in the radiation calculations, although at the time there were no experimental data for the particular alloy used to substantiate this value. Subsequent experiments resulted in a value of 0.03 for these surfaces. However, irregularities due to piping and supports would increase the effective emissivity so that 0.04 appears to be a reasonable value.

\subsection{Residual Gas Conduction}

The residual gas conduction was calculated from an equation derived by S. S. Kistler [8]. In slightly modified form this equation can be written,

where

$$
\dot{q}=0.374 C_{v} \sqrt{\frac{\bar{M}}{T_{m}}} \frac{T_{2}-T_{1}}{\frac{L}{l_{1}}+\left(\frac{2}{\alpha}-1\right) \frac{1}{P}},
$$

$\dot{q}=$ watts per square inch of inner surface,

$C_{v}=$ specific heat of the residual gas at constant volume in joules per gram per degree $\mathrm{K}$,

$T_{m}=\left(T_{1}+T_{2}\right) / 2=$ mean temperature of the gas in degrees $\mathrm{K}$,

$T_{1}=$ temperature of the inner surface in degrees $\mathrm{K}$,

$T_{2}=$ temperature of the outer surface in degrees $\mathrm{K}$,

$L=$ perpendicular distance between inner and outer surface in inches,

$l_{1}=$ mean free path of the gas in inches at $T_{m}$ and a pressure of $1 \mathrm{~mm} \mathrm{Hg}$,

$P=$ pressure of the gas in $\mathrm{mm} \mathrm{Hg}$,

$\alpha=$ accommodation coefficient factor of the surfaces,

$M=$ molecular weight of gas.

It should be noted that $\dot{q}$, the rate of energy flow per unit of area, is used directly, because at low pressures the concept of specific conductivity for the gas is meaningless. If the residual gas is air the value of $l_{1}$ will be $l_{1}=6.56 \times 10^{-6} T_{m}$ in., whereas if the residual gas should be hydrogen, the value of $l_{1}$ would be $l_{1}=12.2 \times 10^{-6} T_{m}$ in. As in the radiation calculations, a correction for the Dewar configuration must be applied. It seems reasonable to use a Christiansen-type correction factor to define an effective accommodation coefficient, $\alpha$.

$$
\frac{1}{\alpha}=\frac{1}{\alpha_{1}}+\frac{A_{1}}{A_{2}}\left(\frac{1}{\alpha_{2}}-1\right)
$$

$A_{1}$ and $A_{2}$ are the areas of the inner and outer surfaces, respectively, and $\alpha_{1}$ and $\alpha_{2}$ are the accommodation coefficients of the surfaces for the residual gas molecules. 


\subsection{Piping and Insulating Support Conduction}

Heat flow through the piping was computed by use of the standard heat-conduction equations and values of thermal conductivity available in the literature [9]. Calculations on insulating support conduction were made at a time when limited data were available on thermal contact resistance (see section 4). An informal communication contained the only data available at that time. A figure of approximately $0.75 \mathrm{mw} / \mathrm{cm}^{\circ} \mathrm{C}$ was given for the equivalent thermal conductivity of a Monel coil. Because stainless steel provides better insulation than Monel, and because the thermal conductivity decreases with decreasing temperature a value of $k=0.5 \mathrm{mw} / \mathrm{cm}^{\circ} \mathrm{C}$ was arbitrarily chosen for the calculations.

\section{Thermal Performance}

\subsection{The 440-Liter Dewar}

The average total heat leak by piping, residual gas and support conduction, and thermal radiation for the 440-liter Dewar, during a period of time exceeding $1 \frac{1}{2}$ years of actual Dewar operation, is shown in table 1 .

\subsection{The 840-Liter Dewar}

A representative set of performance data for the 840-liter Dewar, over an operational period of 6 months, is given in table 2 .

Thus it is seen that under comparable conditions$10^{-5} \mathrm{~mm} \mathrm{Hg}$ insulating vacuum and $50^{\circ}$ to $60^{\circ} \mathrm{F}$ ambient temperature the hydrogen capacity, hydrogen heat leak, and nitrogen heat leak of the 840liter Dewar is approximately twice that of the 440liter Dewar. The daily evaporation of liquid hydrogen expressed as a percentage of the total capacity is nearly the same for both vessels. With similar design objectives some improvement percentagewise should be expected in the performance of the larger vessel. In this case, however, more stringent mechanical service conditions resulted in more heat flow through insulating supports and nullified such improvement.

\section{Refrigeration}

It is frequently desirable to store liquid hydrogen without loss. For short periods this may be accomplished by sealing the hydrogen container and allowing a moderate pressure rise. In Dewars of the type discussed here, storage durations of 1 week or more result in a pressure increase of about $1 \mathrm{~atm}$ within the hydrogen system when the hydrogen container is initially about 90 percent full of liquid.

TABLe 2. Performance data for 840-liter Dewar

\begin{tabular}{|c|c|c|c|c|c|}
\hline \multirow[b]{2}{*}{$\begin{array}{l}\text { Residual } \\
\text { pressure }\end{array}$} & \multirow{2}{*}{$\begin{array}{l}\text { Outer shell } \\
\text { tempera- } \\
\text { ture }\end{array}$} & \multicolumn{2}{|c|}{ Liquid hydrogen } & \multicolumn{2}{|c|}{ Liquid nitrogen } \\
\hline & & Heat leak & $\begin{array}{l}\text { Daily evap- } \\
\text { oration (per- } \\
\text { centage of } \\
\text { total } \\
\text { capacity) }\end{array}$ & Heat leak & $\begin{array}{c}\text { Daily evap } \\
\text { oration }\end{array}$ \\
\hline$m m \underset{10^{-5}}{\mathrm{Hg}}$ & ${ }^{\circ} F$ & $\begin{array}{l}w \\
2.5\end{array}$ & $\begin{array}{c}\% \\
0.80\end{array}$ & $\begin{array}{l}w \\
118.0\end{array}$ & $\begin{array}{l}\text { Liters } \\
63.2\end{array}$ \\
\hline
\end{tabular}

To keep hydrogen without loss indefinitely, it is necessary to periodically refrigerate the hydrogen to prevent excessive pressure rise in the hydrogen shell. Several refrigeration schemes have been proposed and developed, which operate on the principle of recondensing the vapor formed from the liquid hydrogen evaporation by circulating a colder gas, used as a refrigerant, through a closed condensing coil. The Bureau has developed a refrigerator that utilizes the principle of reliquefying the vapor formed from evaporation of liquid hydrogen by circulating the hydrogen vapor in a simple Joule-Thomson-type hydrogen liquefier. A high refrigeration efficiency is achieved. The components of this refrigeration system include the usual compression, purification, purging, and control equipment, along with the necessary heat exchangers and expansion valve.

The 840-liter Dewar is capable of being refrigerated by equipment using this new application of the Joule-Thomson process. The only components operating at low temperatures, and thus requiring insulation, are the heat exchangers and expansion valve. These were mounted in the Dewar insulating vacuum space. The remainder of the refrigeration

TABLE 1. Average total heat leak

\begin{tabular}{|c|c|c|c|c|c|c|c|}
\hline \multirow{3}{*}{$\begin{array}{c}\text { Residual } \\
\text { pressure a }\end{array}$} & \multirow{3}{*}{$\begin{array}{l}\text { Outer } \\
\text { shell } \\
\text { tempera- } \\
\text { ture }\end{array}$} & \multicolumn{2}{|c|}{ Liquid hydrogen } & \multicolumn{4}{|c|}{ Liquid nitrogen } \\
\hline & & \multirow{2}{*}{ Heat leak } & \multirow{2}{*}{$\begin{array}{l}\text { Daily evapora- } \\
\text { tion (percent- } \\
\text { age of total } \\
\text { capacity) }\end{array}$} & \multicolumn{2}{|c|}{ Without additional shields } & \multicolumn{2}{|c|}{ With additional shields } \\
\hline & & & & Heat leak & $\begin{array}{c}\text { Daily } \\
\text { evaporation }\end{array}$ & $\begin{array}{l}\text { Heat } \\
\text { leak o }\end{array}$ & $\begin{array}{c}\text { Daily } \\
\text { evaporation }\end{array}$ \\
\hline$m m \underset{10^{-4}}{\mathrm{Hg}}$ & ${ }_{60}^{\circ} \mathrm{F}$ & $\begin{array}{r}u \\
3.7\end{array}$ & $\begin{array}{r}\% \\
2.29\end{array}$ & $w$ & Liters & $u$ & Liters \\
\hline $5 \times 10^{-5}$ & 60 & 2.0 & 1. 24 & 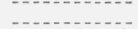 & & & - n \\
\hline $10^{-5}$ & 60 & b $1.3(1.4)$ & b $0.81(0.89)$ & $\mathrm{b}(63.8)$ & $\mathrm{b}(34.2)$ & & \\
\hline $10^{-6}$ & 60 & b $0.9(0.8)$ & b. $56(0.46)$ & b $62.5(61.1)$ & ь $33.5(32.7)$ & 52.0 & 27.8 \\
\hline
\end{tabular}

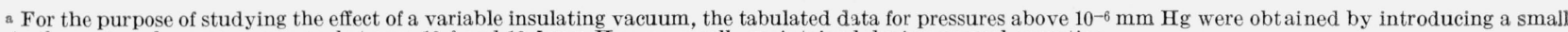
leak to the system, because a vacuum between $10^{-6}$ and $10^{-7} \mathrm{~mm} \mathrm{Hg}$ was usually maintained during normal operation.

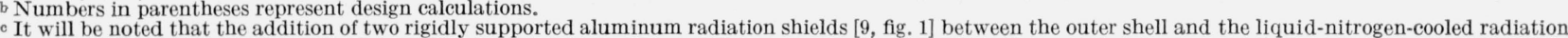
shield reduced the actual heat leak to the liquid nitrogen shield approximately 16 percent. 
equipment is mounted on a dolly, which can be brought easily to the Dewar and connected. Construction of the refrigerator in this manner has resulted in maximum efficiency and simplicity because all connections are warm and the Dewar insulating vacuum is utilized to insulate all low-temperature components of the refrigeration cycle.

A detailed description of this reliquefying hydrogen refrigerator is planned for a subsequent report.

\section{Conclusions}

The National Bureau of Standards has developed rugged, lightweight vessels for storing and transporting liquid hydrogen. These vessels have a very low loss rate. Techniques employed in this development include vacuum-tight aluminum welding, joining aluminum to stainless steel, the use of novel insulating supports, and methods for improving the reflectivity of metallic surfaces. It appears entirely feasible, by further refinements in producing surfaces of high reflectivity and employing mechanical designs with less support conduction, to effect a still further improvement, making possible the low-loss transportation of liquid helium.

\section{References}

[1] Government erects $\$ 3,500,000$ low temperature laboratory, Refrig. Eng. p. 1082 (1953).

[2] Donald P. Smith, Hydrogen in metals (Univ. Chicago Press, 1948).

[3] H. W. Gillette, The behavior of engineering metals, p. 353 (John Wiley \& Sons, Inc., New York, N. Y., 1951).

[4] Russell B. Scott (private communication).

[5] R. P. Mikesell and R. B. Scott, Heat conduction through insulating supports in very low temperature equipment, J. Research NBS 5\%, 371 (1956) RP2726.

[6] Morton C. Smith and David D. Rabb (private communication).

[7] Max M. Jakob and G. A. Hawkins, Elements of heat transfer, 1st ed., p. 125 (John Wiley \& Sons, Inc., New York, N. Y., 1942).

[8] S. S. Kistler, The relation between heat conductivity and structure in Silica Aerogel, J. Phys. Chem. 39, 79 (1935).

[9] Robert L. Powell and William L. Blanpied, Thermal conductivity of metals and alloys at low temperatures, NBS Circ. 556 (1954).

\section{An Improved Vessel}

\section{A. F. Schmidt and B. W. Birmingham}

Subsequent to the work reported in the preceding sections, the 440-liter liquid-hydrogen Dewar was converted in capacity and design to a 500-liter Dewar with several predominant modifications and improvements. A comparison of figures 1 and 7 will service to illustrate these changes. In brief, the aluminum 440-liter spherical container was replaced with a 500-liter stainless-steel dish-ended cylindrical tank, externally silver-sprayed in order to increase the surface reflectivity. The vertical stainlesssteel center support tube was decreased in wall thickness to $0.016 \mathrm{in}$. (one-fifth of its former value), and lateral motion of the inner container with respect to its radiation shield was nullified by 2 sets of 3 stainless-steel aircraft cables, $3 / 32$ in. in diameter, which replaced the stainless-steel coil strips previously used; $1 / 8-i n$. aircraft cables also replaced the entire bottom coil assembly. The rigidly supported double set of "floating radiation shields" was exchanged for a single "floating shield" attached to the outer shell by 3 long stainless-steel tubes, and Teflon bumpers spaced the shield from the nitrogen shell at the top. In order to reduce the over-all height of the assembly, vent lines and valves were brought through the side of the Dewar.

The thermal performance of this 500-liter Dewar over a 1-month period is given in table 3 .

TABLE 3.-Thermal performance of 500-liter Dewar

\begin{tabular}{|c|c|c|c|c|c|}
\hline \multirow[b]{2}{*}{$\begin{array}{l}\text { Residual } \\
\text { pressure }\end{array}$} & \multirow[b]{2}{*}{$\begin{array}{l}\text { Outer shell } \\
\text { termpera- } \\
\text { ture }\end{array}$} & \multicolumn{2}{|c|}{ Liquid hydrogen } & \multicolumn{2}{|c|}{ Liquid nitrogen } \\
\hline & & $\begin{array}{l}\text { Heat } \\
\text { leak }\end{array}$ & $\begin{array}{l}\text { Daily evapo- } \\
\text { ration (percent- } \\
\text { age of total } \\
\text { capacity) }\end{array}$ & $\begin{array}{l}\text { Heat } \\
\text { leak }\end{array}$ & $\begin{array}{l}\text { Daily } \\
\text { evapora- } \\
\text { tion }\end{array}$ \\
\hline$m \underset{10^{-6}}{m} \mathrm{Hg}$ & $\begin{array}{l}\circ F \\
96\end{array}$ & $\begin{array}{c}w \\
0.47\end{array}$ & $\begin{array}{c}\% \\
0.26\end{array}$ & $\begin{array}{c}w \\
29.5\end{array}$ & $\begin{array}{c}\text { Liters } \\
15.8\end{array}$ \\
\hline
\end{tabular}

A note of interest may be inserted here relative to one aspect of safety involved in the use of this vessel. Users have been concerned about the consequences of sudden loss of insulating vacuum for containers of this type. A dangerous rise of pressure was feared. In this container a 1-in.-diameter hole was suddenly opened in the outer wall of the Dewar vacuum space, resulting in the entire contents - both hydrogen and nitrogen - evaporating and being vented through the respective $3 / 4$-in. vent lines. The pressure rise resulting from the rapid evaporation did no damage.

In conclusion, these changes confirm that application of design modifications recommended in section 10 were justified. A liquefied-gas-storage vessel has been developed with a daily hydrogen evaporation rate of approximately $1 / 4$ percent of the total capacity in the 500-liter size range. It is planned to evaluate this vessel as a liquid-helium-storage Dewar. 


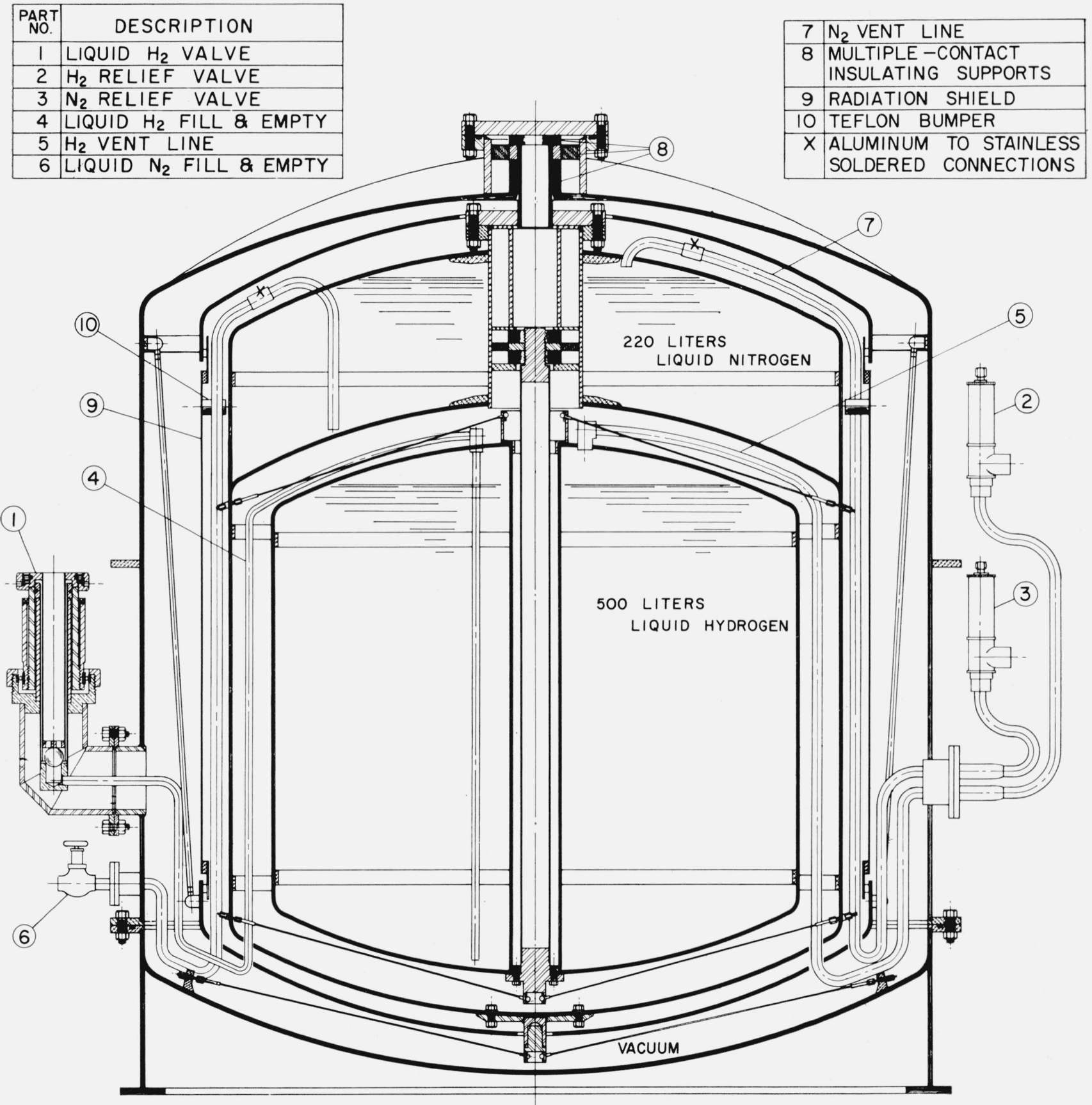

Figure 7. 500-liter liquid hydrogen Dewar.

Boulder, Colo., October 27, 1955. 